\title{
Optimizing Cycle Time of CFT Outer in Injection Moulding Process
}

\author{
Likitha J \\ Mtech, Student \\ Department of Tool engineering \\ Government tool room and training centre \\ Mysore, India
}

\begin{abstract}
Optimization of cycle time in injection moulding process plays a critical role in plastic part production to increase process efficiency. At the same time the price and quality of the finished part will not be affected. This paper explains the cycle time optimization of CFT Outer. The process parameters such as cooling time, cavity balancing, gate area improvement, and Injection time are optimized in which it contributes more in the cycle time.

Experimental verification has been done with scientific injection moulding process-six step study in Injection moulding machine. The experiment results showed a way to achieve the goal of cost effective way of optimizing the process
\end{abstract}

Keywords - CFT outer, scientific injection moulding, six step study, cooling time, cavity balancing, gate improvement.

\section{INTRODUCTION}

Injection moulding is one of the most widely used and important processes for the manufacturing of plastic part. The principle advantage of this process is to produce large volume of components in a short time. The injection moulding process consists of melting of polymer and then injecting the melt into the cavity in the moulds. After reaching the cooling temperature the part is ejected from the mould. The injection, packing, cooling and component ejection are the main phases of the injection moulding cycle. The main objective of this paper is to reduce the cycle time and increase the productivity. By varying parameters like injection time, speed, holding time, pressure, cooling.

\section{METHODOLOGY}

The scientific injection moulding technique which includes six step study is used to optimize the process. The scientific injection moulding is used in the production where small variations in moulding variables can severely impact the process or finished product which leads to increase in the productivity. The 6-step study refers to the viscosity curve, cavity balance, gate seal, process window, pressure drop, cooling time.

The 6-step study: the viscosity (Rheology) curve, gate freeze study and pressure drop analysis were the three experiments conducted as part of scientific moulding studies. The Molding Area Diagram (MAD) has reference in some early texts including in Rosato's Hand Book of injection Molding', which was not always considered [1]. Suhas kulkarni identified the MAD as the most effective and crucial step for deciding the robustness of the moulding process, cavity balancing is also important step [2].

\author{
Dr. N Ramesha \\ Principal of PG studies \\ Department of Tool engineering \\ Government tool room and training centre \\ Mysore, India
}

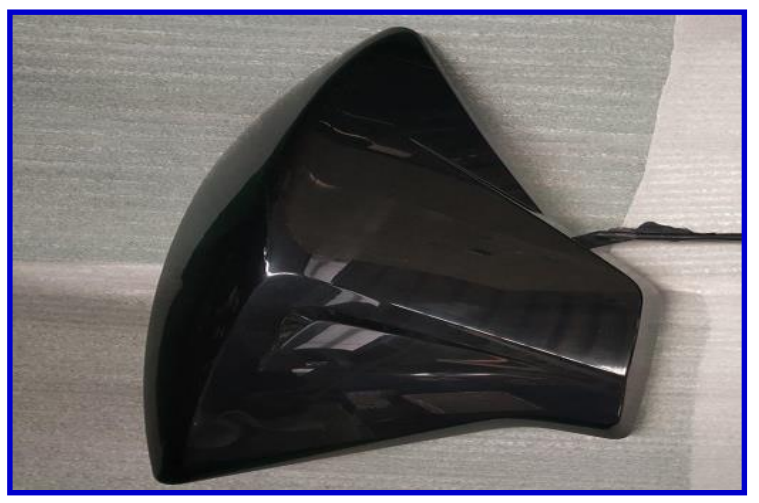

Fig-1: CFT OUTER

Viscosity curve-. To check the injection speed setting in the Newtonian range. Set the holding pressure to zero, make a short shot that fill $95 \%$ and note the fill time and peak injection pressure. Now lower the injection speed to $90 \%, 80 \%$ so on and note the fill time and peak injection pressure. Obtain the intensification ratio of the screw from the machine manufacturer the value is 10 .

Viscosity = Peak Injection pressure $*$ fill time * Intensification factor

Plot the graph Injection speed v/s Viscosity

\begin{tabular}{|c|c|c|c|c|}
\hline $\begin{array}{c}\text { Speed } \\
(\mathrm{mm} / \mathrm{s})\end{array}$ & $\begin{array}{c}\text { Fill } \\
\text { time(sec) }\end{array}$ & $\begin{array}{c}\text { Pressure } \\
(\mathrm{Mpa} .)\end{array}$ & $\begin{array}{c}\text { Intensification } \\
\text { ratio }\end{array}$ & Viscosity \\
\hline 15 & 8.07 & 110.1 & 10 & 8885.1 \\
\hline 20 & 6.07 & 109.8 & 10 & 6664.9 \\
\hline 30 & 4.07 & 109.6 & 10 & 4460.7 \\
\hline 40 & 3.06 & 110.1 & 10 & 3369.1 \\
\hline 50 & 2.45 & 111.2 & 10 & 2735.5 \\
\hline 60 & 2.06 & 113.1 & 10 & 2329.9 \\
\hline
\end{tabular}

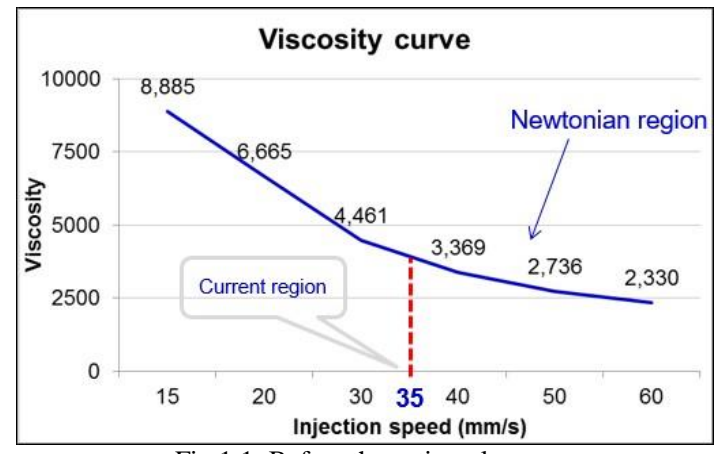

Fig 1.1: Before the action plan 


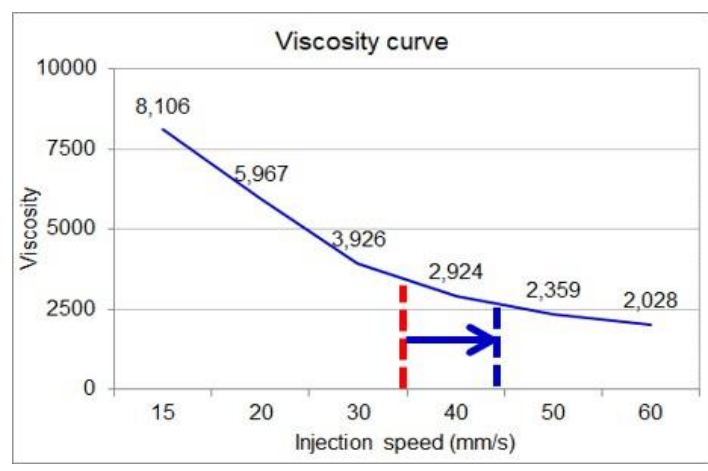

\section{Observations}

Fig 1.2: After the action plan

The injection speed to be set above $45 \mathrm{~mm} / \mathrm{sec}$ which is in the Newtonian region since at this point the rate of change of viscosity is minimum. When the value is set and production is started the voids were found in the parts and hence the injection speed is reduced to $35 \mathrm{~mm} / \mathrm{sec}$ where the parts were with no voids. From the viscosity curve the optimized injection pressure is determined

Cavity balancing-to understand the rate of melt injection the cavity balancing study is done. The weight graph of the short shots from all cavities offers details on the filling balance between the cavities. A balanced filling of cavities guarantees an equal amount of material that is packed into the cavities, resulting the consistency of cavity to cavity. Set the speed of injection and time of holding that is obtained from the viscosity curve. Next, generate a short shot sequence, and record the weights of the cavity for each shot as in the above step. Depending on the size of the component, it is important to record at least 3 to 4 progressing shots, starting with the smallest short shot parts that can be make.

\begin{tabular}{|c|c|c|}
\hline TRANSFER(MM) & $\begin{array}{c}\text { \% } \\
\text { OF } \\
\text { FILL }\end{array}$ & $\begin{array}{c}\text { \% OF } \\
\text { VARIATION }\end{array}$ \\
\hline 125 & 8.6 & 7 \\
\hline 115 & 16.9 & 8.1 \\
\hline 100 & 29 & 11.2 \\
\hline 75 & 48.8 & 12.7 \\
\hline 50 & 68.5 & 11.3 \\
\hline 25 & 88 & 8.2 \\
\hline
\end{tabular}

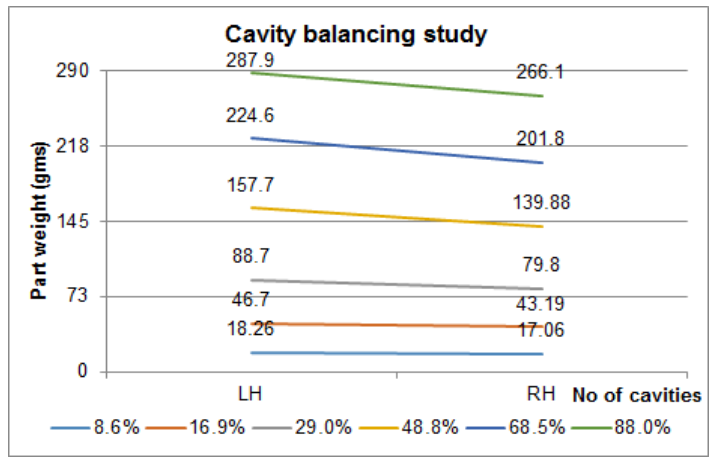

Fig 2.1: Before the action plan

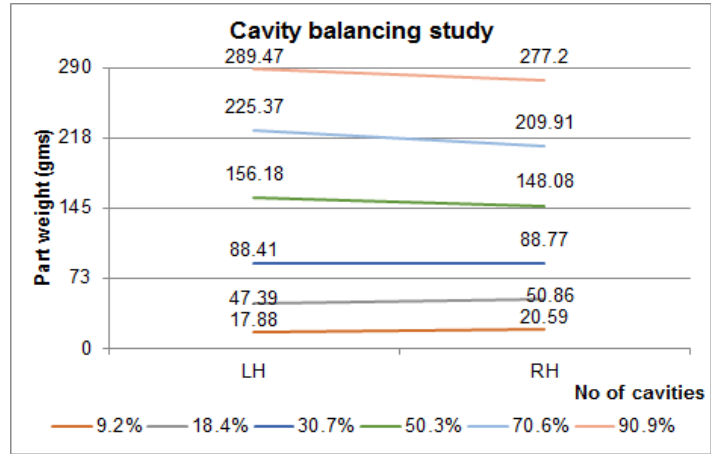

\section{Observations}

Fig 2.2: After the action plan

During the conduction of experiment, it is seen that the left-hand cavity fills faster than that of the right-hand cavity. The mould has to be inspected for the change in dimensions between the right-hand cavity and left-hand cavity.

\section{Shear rate calculations volume flow rate $(Q)$}

shear rate of rectangular gate

$$
=\frac{\text { one cavity volume }}{(\text { fill time } * \text { no. of gates } / \text { cavity }}
$$

$$
=\frac{(6 * Q)}{(\text { gate width } * \text { gate thickness } 2)}
$$

For left hand side gate:

Volume flow rate $(\mathrm{Q})=306.1 /(3.77 * 1)=81.2 \mathrm{cc} / \mathrm{sec}$

Shear rate rectangular gate $=(6 * 81.2 * 1000) /\left(15.55 * 2.03^{2}\right)$ $=7525 / \mathrm{sec}$

\section{For right hand side gate:}

Volume flow rate $(Q)=303 /(3.77 * 1)=80.3 \mathrm{cc} / \mathrm{sec}$

Shear rate rectangular gate $=(6 * 80.3 * 1000) /\left(10.42 * 2.03^{2}\right)$ $=11345 / \mathrm{sec}$

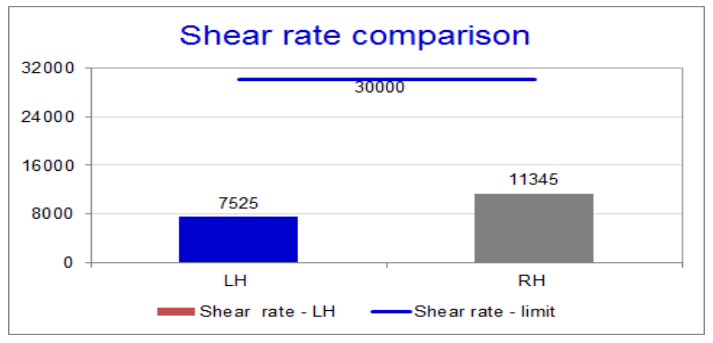

Fig 2.3: Shear rate

The shear rate of $\mathrm{RH}$ is more when compared to $\mathrm{LH}$

Pressure drop study-to find where max pressure drop occurs. Set the injection speed and holding pressure as obtained from viscosity curve next set the transfer position to push the flow through the stages: nozzle, sprue, runner, $1 / 3^{\text {rd }}, 2 / 3^{\text {rd }}$ and complete fill of part and record the peak pressure in each stages. Plot a graph of the peak pressure versus the flow section to generate the pressure drop graph. 


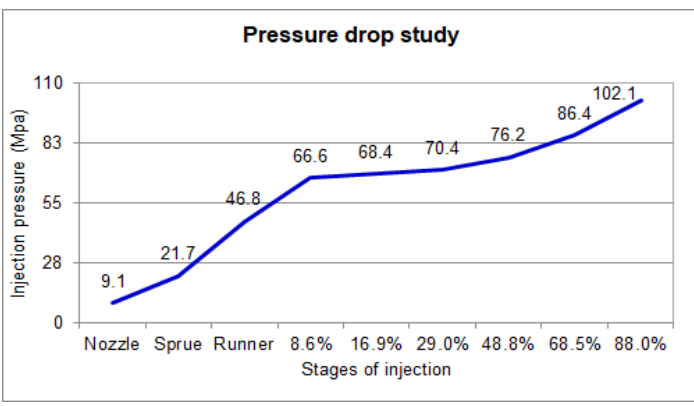

Fig 3.1: Before the action plan

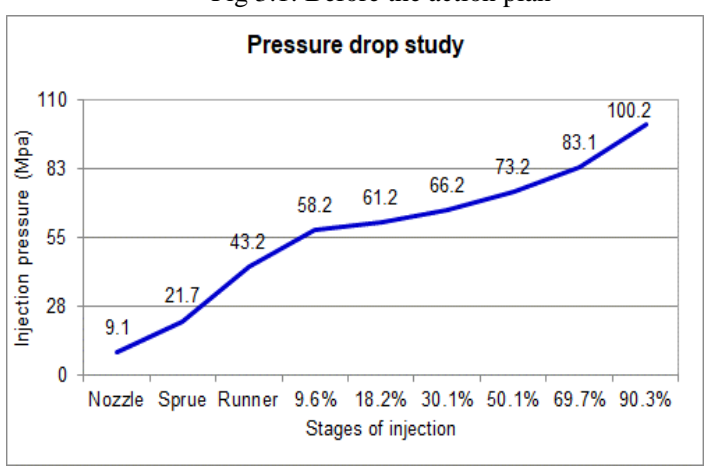

Fig 3.2: After the action plan

\section{Observations}

The experiment is conducted and graph is plotted. It is found that the pressure drop is high across the gate about $45 \mathrm{Mpa}$. This gives us the justification that the area of the gate is small and has to be improved

Process window- Is used to determine the holding pressure and the temperature of melt. The analysis of process window is carried out to find the limits within which aesthetically acceptable parts can be molded

\begin{tabular}{|c|c|c|}
\hline $\begin{array}{c}\text { MELT } \\
\text { TEMPERATURE }\left({ }^{\circ} \mathrm{C}\right. \\
\text { ) }\end{array}$ & $\begin{array}{c}\text { PRESSURE(FLASH } \\
\text { ) PRESSURE(SINK } \\
\text { ) }\end{array}$ \\
\hline 235 & 112 & 90 \\
\hline 265 & 88 & 63 \\
\hline
\end{tabular}

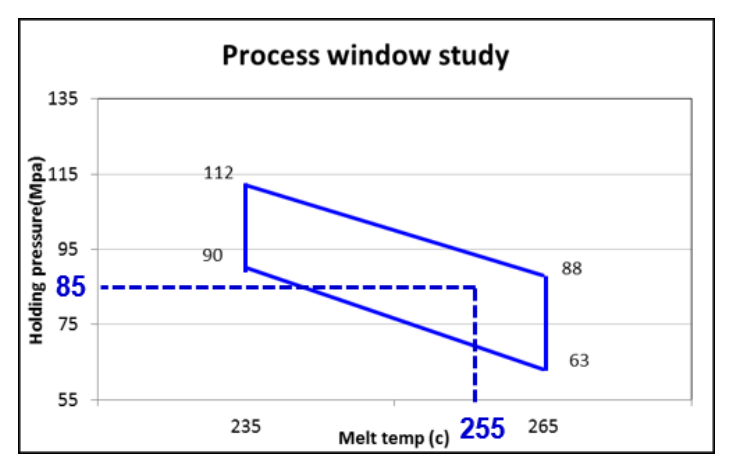

Fig 4.1: Before the action plan

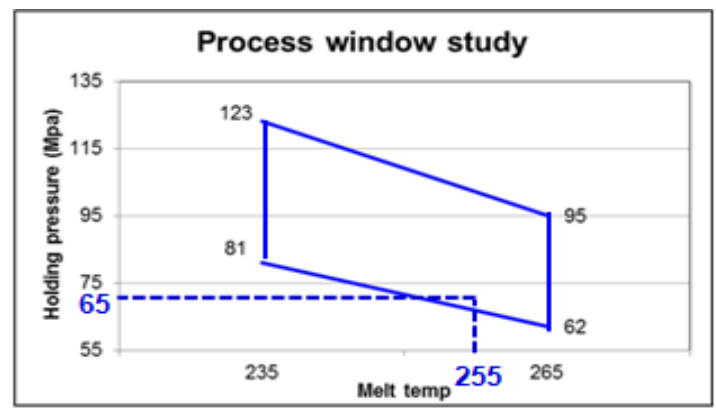

Fig 4.2: After the action plan

\section{Observations}

The experiment is conducted and pressure and temperature are noted and connected to get the process window. It is seen that the process window is narrow and the possibilities of the part getting defects is more. The parts and mould has to be analyzed in IR image for better understanding of the process window.

Gate seal study-to determine the holding pressure at which the gate gets seal. Set the injection speed as viscosity curve. Set the process to centre of the process window. Take at least 10 shots by increasing the holding time. Then take the shots and record the weight of parts. The gate seal time is the time at which the part weight stays constant.

\begin{tabular}{|c|c|c|}
\hline $\begin{array}{c}\text { HOLDING } \\
\text { TIME(SEC) }\end{array}$ & $\begin{array}{c}\text { PART } \\
\text { WEIGHT(GMS) }\end{array}$ & REMARKS \\
\hline 4 & 651.3 & Sink \\
\hline 5 & 655.3 & Sink \\
\hline 6 & 658.1 & Sink \\
\hline 7 & 659.6 & $\begin{array}{c}\text { Low intense } \\
\text { sink }\end{array}$ \\
\hline 8 & 660.5 & Ok \\
\hline 9 & 661.1 & Ok \\
\hline
\end{tabular}

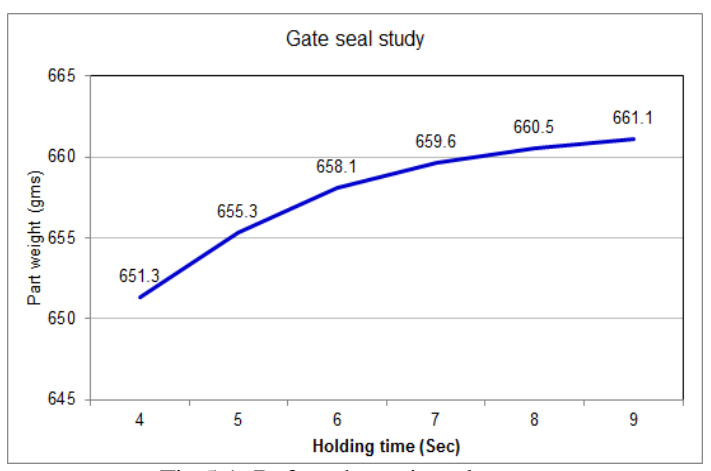

Fig 5.1: Before the action plan

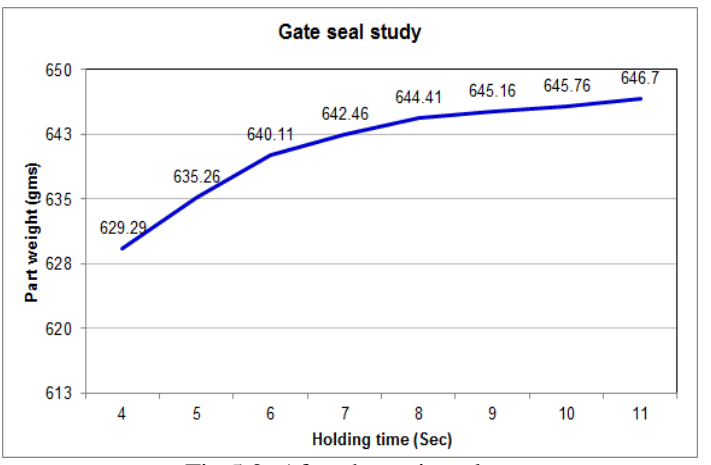

Fig 5.2: After the action plan 


\section{Observation}

The graph gives the details of the part weight and the holding time. For different holding time the weight of the part changes and the sink is formed until the holding time of $7 \mathrm{sec}$. Hence the holding time is set at $8 \mathrm{sec}$ after injection.

Cooling time study- Cooling time study-this gives the efficiency of cooling. Calculate the discharge of the coolant flow at the inlet and outlet of the mould along the individual cooling lines using flow meter device. Calculate the surface area of the cooling channel using flow diameter (from the design). Find out the velocity of the flow using continuity equation.

Action plan- to improve the cooling line efficiency the descalling of the cooling line is done. Air vents are improved in both the cavities. To improve the cavity balancing and to reduce the shear rate of $\mathrm{RH}$ the gate area of $\mathrm{RH}$ is increased

After implementing these changes the six step-study is performed again to compare the difference. Future DOE is conducted to validate the result

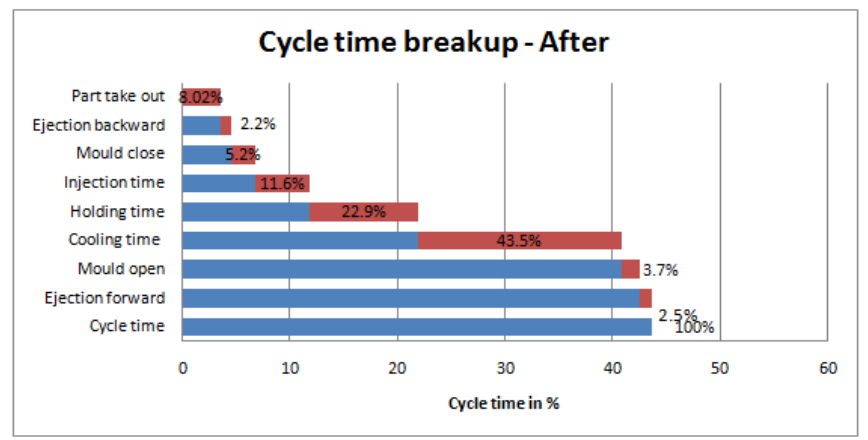

Fig 6.1: Before the action plan

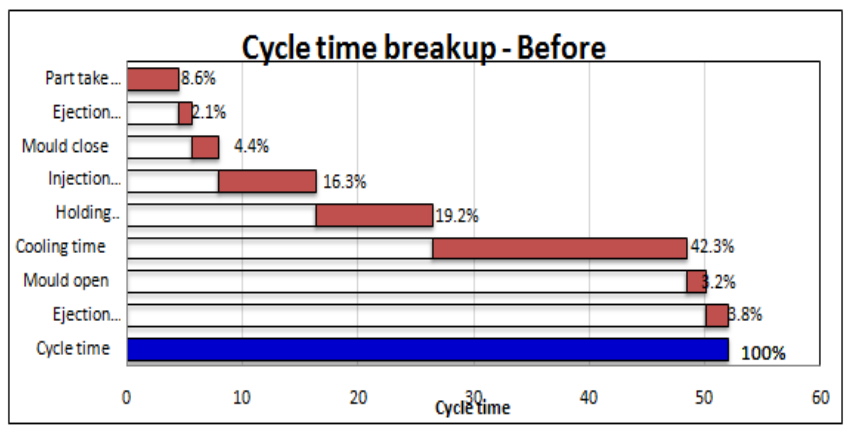

Fig 6.2: After the action plan

\section{RESULT}

Cooling time is reduced for about $16 \%$. Over all viscosity dropped by $8.76 \%$.fill variation between the cavities dropped from $8.2 \%$ to $4.4 \%$. Pressure drop across the runner area is reduced by $7.7 \%$.Process window become larger by $60 \%$. Gate seals at $10 \mathrm{sec}$ after injection time due to increase in the gate area and the reduction in injection time.

\section{CONCLUSION}

In this study optimization of process parameters and cycle time reduction in the injection molding process using scientific injection molding technique six step study, Which has given many positive outcomes during the process that includes reduction in the part weight, which has been specified by the mould designer, reducing the energy consumption of the machine, reduction in overall cost per part has been achieved.

\section{REFERENCES}

[1] Dominick V. Rosato, Donald V. Rosato, Marlene G. Rosato. Injection Molding handbook. Carl Hanser Verlag $\mathrm{GmbH} \& \mathrm{Co}$ $\mathrm{KG}, 2010$

[2] Suhas Kulkarni. Robust Process Development and Scientific Molding Theory and Practice. Springer Science \& Business Media, 2000

[3] Optimizing Cycle Time Of Dvd-R Injection Moulding Machine. Neeraj Singh Chauhan, Shahzad Ahmad

[4] Parameter Optimization of Injection Molding of Polypropylene by using Taguchi Methodology M. V. Kavade1, S. D. Kadam2 